Kong. Res. J. 3(1) : 1-5, 2016

ISSN 2349-2694

Kongunadu Arts and Science College, Coimbatore.

\title{
ANTIMICROBIAL PROPERTIES OF LANTHANUM ALUMINATE NANOPARTICLES
}

\author{
Gayathri S $^{1}$., R. Ranjithkumar ${ }^{2}$, A.S. Balaganesh ${ }^{1}$ and B. Chandar Shekar ${ }^{\mathbf{1}}$ \\ 1Department of Physics, Kongunadu Arts and Science College, Coimbatore-29. \\ ${ }^{2}$ The NEAR Foundation, The Nilgiris, Tamilnadu, India. \\ *Email: chandar.bellan@gmail.com
}

\begin{abstract}
The sol-gel route synthesized LA-NPs were tested for antimicrobial properties against different human pathogenic bacteria and fungi. The test organisms used were clinical isolates viz., Streptococcus pyogenes, Staphylococcus aureus, Escherichia coli, Klebsiella nemoniae and the human fungal pathogens like Candida albicans and Trichoderma viride. The LA- NPs achieved maximum activity against S. aureus compared with other three tested organisms such as S. pyogenes, E. coli and K. pneumonia. It also showed very good antimicrobial properties against studied fungi. At the concentration $1 \mathrm{mg} / \mathrm{ml}$ LA-NPs impregnated filter paper disk achieved maximum activity against human pathogen.
\end{abstract}

Keywords: Antimicrobial activity, Lanthanum aluminate nanoparticles, human pathogens.

\section{INTRODUCTION}

The application of nanomaterials in biotechnology merges the fields of material science and biology. Nanoparticles provide a mostly useful platform, demonstrating distinctive properties with potentially wide-ranging applications in therapeutic field (Gao et al., 2004). The advancements in the area of nanoparticles technology and nanotechnology have offered an understanding and controlling of the materials at atomic and molecular levels. It has also assisted in fabricating advanced materials with added optical, electrical, magnetic and biological properties for pharmaceutical and biomedical applications (Iconaru et al., 2012). Nanovectors in the field of delivery are promising novel tools for controlled release of drug (Maya et al., 2015). Bio macromolecule external recognition by nanomaterials as artificial receptors provides a potential tool for controlling cellular and extracellular processes for numerous biological applications such as enzymatic inhibition, transcription regulation delivery and sensing. The biological application of nanoparticles depending on the core size of material providing a suitable platform for the interaction of nanomaterial with biomolecules (Hostetler et al., 1998). Nanomaterials have already been used for a wide range of applications both in-vitro and in-vivo. The surface and core properties of nanomaterials can be engineered for individual and multimodal applications, including biomolecular recognition, therapeutic delivery such as antimicrobial, anticancer, biosensing and bio imaging (Mrinmoy et al., 2008).
In this world of emerging nanotechnology, one of the primary concerns is the potential environment impact of nanoparticles. An efficient way to estimate nanotoxicity is to monitor the response of bacteria exposed to these particles. Resistance of bacteria to bactericides and antibiotic has increased in recent years due to the development of resistant strains. Some antimicrobial agents are extremely irritant and toxic and there is much interest in finding ways to formulate new type of safe and cost-effective biocidal materials (Brayner, 2008). Earlier studies have been shown that antimicrobial formulations in the form of nanoparticles could be used as effective bactericidal materials. Recently, it has been reported that highly reactive metal oxide nanoparticles exhibit excellent biocidal active against Gram positive and Gram negative bacteria (Kim et al., 2007; Savithramma et al., 2011; Kagan et al., 2002).

Bacteria are generally characterized by a cell membrane, cell wall, and cytoplasm. The cell wall lies outside the cell membrane and is composed mostly of a homogeneous peptidoglycan layer. The cell wall maintains the osmotic pressure of the cytoplasm as well the characteristic cell shape. Gram positive bacteria have one cytoplasmic membrane with multilayer of peptidoglycan polymer and a thicker cell wall $(20-80 \mathrm{~nm})$. Whereas gram-negative bacteria wall is composed of two cell membranes, an outer membrane and a plasma membrane with a thin layer of peptidoglycan with a thickness of 7-8 nm. Nanopartilces size within such ranges can readily pass through the peptidoglycan and hence are highly susceptible to damage (Fu et al., 2005; 
Amna et al., 2015). Hence, the preparation, characterization and surface modification of nanosized particles open the possibility of formulation of a new generation of bactericidal materials (Duncan, 2011). The nanoparticles present a highly attractive platform for a diverse array of biological applications. Hence the present study focuses the antimicrobial properties of sol gel route synthesized Lanthanum Aluminate Nanoparticles (LA-NPs) against different human pathogenic bacteria and fungi.

\section{MATERIALS AND METHODS}

\subsection{Lanthanum Aluminate Nanoparticles (LA-NPS)}

Our research group already reported synthesis of LA-NPs by sol-gel method and obtained nanoparticles were characterized by X-Ray Diffraction (XRD), Scanning Electron Microscope (SEM) and Energy Dispersive Spectrum (EDS) (Gayathri and Chandar Shekar, 2015). The synthesized LA-NPs were tested for antimicrobial properties against different human pathogenic bacteria and fungi.

\subsection{Test microorganisms}

The test organisms used were clinical isolates viz., Streptococcus pyogenes, Staphylococcus aureus, Escherichia coli and Klebsiella nemoniae. The human fungal pathogens like Candida albicans and Trichoderma viride, which were obtained from Department of Microbiology, Raja Muthaiyah medical college, Annamalai University. The bacterial and the fungal cultures were maintained on nutrient agar medium and potato dextrose agar (PDA) medium respectively. The bacterial cultures were maintained on nutrient broth (Table I) at $37^{\circ} \mathrm{C}$ and fungus was maintained on Potato dextrose agar (Table. II) at $28^{\circ} \mathrm{C}$.

Table 1. Composition of Nutrient Broth (NA) medium

$\begin{array}{ll}\text { Peptone } & 5.0 \mathrm{~g} \\ \text { Beef extract } & 3.0 \mathrm{~g} \\ \text { Agar } & 15.0 \mathrm{~g} \\ \text { Distilled water } & 1000 \mathrm{ml} \\ \text { pH } & 7.0\end{array}$

Table 2. Composition of Potato Dextrose Agar (PDA) medium

$\begin{array}{ll}\text { Potato } & 200.0 \mathrm{~g} \\ \text { Dextrose } & 20.0 \mathrm{~g} \\ \text { Agar } & 15.0 \mathrm{~g} \\ \text { Distilled water } & 1000 \mathrm{ml} \\ \text { pH } & 6.2\end{array}$

\subsection{Preparation of inoculum}

The gram positive bacteria Streptococcus pyogenes ( $S$. pyogenes), Staphylococcus aureus ( $S$. aureus) and gram negative bacteria Escherichia Coli (E. coli), Klebsiella pneumoniae (K. pneumoniae) were pre-cultured in Nutrient Broth (NB) over night in a rotary shaker at $37^{\circ} \mathrm{C}$, centrifuged at $10,000 \mathrm{rpm}$ for $5 \mathrm{~min}$, pellet was suspended in double distilled water and the cell density was standardized spectrophotometrically $\left(\mathrm{A}_{610} \mathrm{~nm}\right)$. The fungal inoculums Candida albicans (C. albicans), Trichoderma viride ( $T$. viride), were prepared from 5 to 10 day old culture grown on Potato Dextrose Agar (PDA) medium. The Petri dishes were flooded with 8 to $10 \mathrm{ml}$ of distilled water and the conidia were scraped using sterile spatula. The spore density of each fungus was adjusted with spectrophotometer $\left(A_{595} \mathrm{~nm}\right)$ to obtain a final concentration of approximately $10^{5}$ spores $/ \mathrm{ml}$.

\subsection{Anti-bacterial activity}

The antibacterial activities of sol-gel route synthesized nanoparticles were tested against both gram positive and gram negative human pathogens by the standard disk diffusion method. In brief, different concentration nanoparticles were prepared by reconstituting with distilled water. The test human pathogens were seeded into respective medium by spread plate method $10 \mu \mathrm{L}(10$ cells $/ \mathrm{ml})$ with the $24 \mathrm{~h}$ cultures of bacteria growth in nutrient broth. After solidification the filter paper disks (4 $\mathrm{mm}$ in diameter) were impregnated with different concentration of LA-NPs $(0.5 \mathrm{mg} / \mathrm{ml}$ and $1 \mathrm{mg} / \mathrm{ml})$. Followed by this step, the nanoparticles impregnated filter papers were placed on test organism-seeded plates. The antibacterial assay plates were incubated at $37^{\circ} \mathrm{C}$ for $24 \mathrm{~h}$. The diameters of the inhibition zones were measured in mille meter (mm).Chloramphenicol (10 $\mu \mathrm{g})$ used as standard for antibacterial test.

\subsection{Anti-fungal activity}

The antifungal activities of sol-gel route synthesized nanoparticles were tested against two pathogens by the standard disk diffusion method. In brief, the potato dextrose agar plates were inoculated with each fungal culture (10 days old) by point inoculation. The filter paper wells $(4 \mathrm{~mm}$ in diameter) impregnated with different concentrations $(0.5 \mathrm{mg} / \mathrm{ml}$ and $0.1 \mathrm{mg} / \mathrm{ml})$ of LANPs. Followed by this step, different concentration nanoparticles impregnated filter paper disk were placed on test organism-seeded plates. The activity was determined after $72 \mathrm{hrs}$ of incubation at $28^{\circ} \mathrm{C}$. The diameters of the inhibition zones were 
measured in mm. Chloramphenicol $(10 \mu \mathrm{g})$ used as positive control.

\section{RESULTS AND DISCUSSION}

\subsection{Antibacterial activity of LA-NPS}

The sol-gel route synthesized LA-NPs were tested against clinically isolated both gram positive and gram negative human pathogenic microorganisms. The zone of inhibition was measured for both standard and LA-NPs coated filter paper and the results depicted in figure 1. It was found that LA-NPs coated filter paper disk shown maximum activity against gram positive organisms compared with gram negative organisms. At the concentration of 0.5 and $1 \mathrm{mg} / \mathrm{ml}$ LA-NPs impregnated filter paper disk achieved maximum activity around 16 and $18 \mathrm{~mm}$ against $S$. aureus respectively. For LA NPs impregnated filter paper disk shown significant activity against gram negative bacteria $E$. coli around 15 and $16 \mathrm{~mm}$ for 0.5 and 1 $\mathrm{mg} / \mathrm{ml}$ concentration.

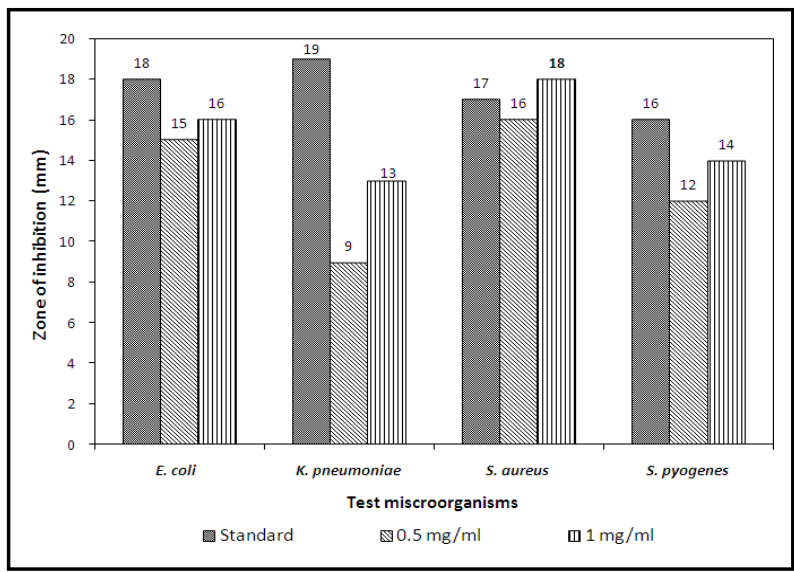

Fig. 1. Antibacterial activity of LA-NPs against pathogenic bacterium

LA-NPs impregnated filter paper disk shown significant antibacterial properties against various pathogens investigated and were compared with control. The diameter of inhibition zones increased for the test pathogen (Fig. 2). Whereas, other two clinically isolated bacteria strains of $K$. pneumoniae and $S$. pyogenes showed zone of inhibition of 9 and $12 \mathrm{~mm}$ at the concentration of $0.5 \mathrm{mg} / \mathrm{ml}$ and 13 and $14 \mathrm{~mm}$ at the concentration of $1 \mathrm{mg} / \mathrm{ml}$ respectively. Whereas, standard antibiotic disk Chloramphenicol obtained 18, 19, 18 and $14 \mathrm{~mm}$ against E. coli, $K$. pneumoniae, $S$. aureus and $S$. pyogenes respectively. The sol-gel route synthesized LA-NPs showed inhibition zone against all the studied bacteria and we found that the synthesized LA-NPs have good antibacterial action against both gram positive and gram negative bacteria.

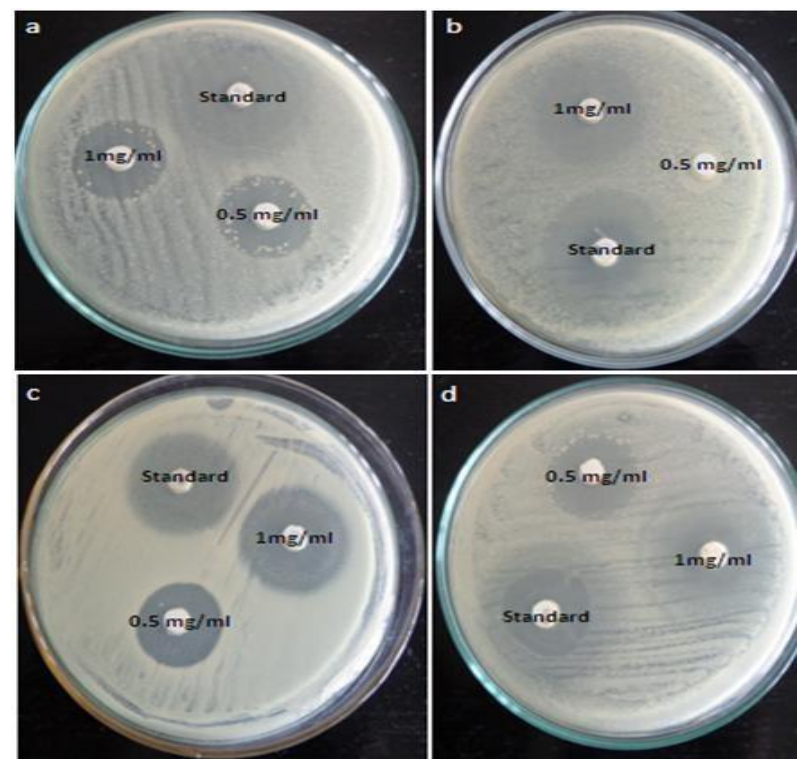

Fig. 2. Antibacterial activity of LA-NPs against human pathogenic

a) E. coli b) K. pneumoniae c) $S$. aureus and d) S. pyogenes

\subsection{Antifungal activity of LA-NPS}

The sol-gel route synthesized LA-NPs were tested against clinically isolated human pathogenic fungus by standard disk diffusion method. The zone of inhibition was measured for both standard and lanthanum aluminate coated filter paper and the zone of inhibition was shown in figure 3 . It was found that lanthanum aluminate coated filter paper disk shown maximum activity against $T$. viride compared with C. albicans. At the concentration of 0.5 and $1 \mathrm{mg} / \mathrm{ml}$ lanthanum aluminate impregnated filter paper disk achieved maximum activity around 5 and $20 \mathrm{~mm}$ against $T$. viride respectively. Whereas, lanthanum aluminate impregnated filter paper disk shown significant activity against $C$. albicans around 3 and $19 \mathrm{~mm}$ for 0.5 and $1 \mathrm{mg} / \mathrm{ml}$ concentration.

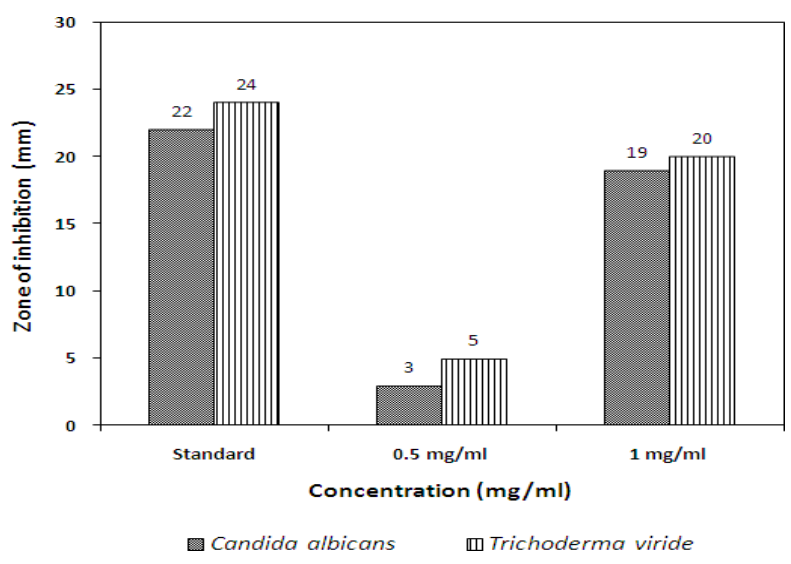

Fig. 3. Antifungal activity of LA-NPs against human pathogenic fungi 
LA-NPs impregnated filter paper disk shown significant antifungal properties against test pathogens investigated and were compared with control. The diameter of inhibition zones increased for the test pathogen at the maximum concentration of $1 \mathrm{mg} / \mathrm{ml}$. whereas, standard antibiotic disk Chloramphenicol obtained 22, and $24 \mathrm{~mm}$ against $C$. albicans and T. viride respectively (Fig. 4). The present experiment clearly revealed that the sol-gel route synthesized lanthanum aluminate showed inhibition zone against the studied human pathogenic fungi and we found that the synthesized lanthanum aluminate have good antifungal action.

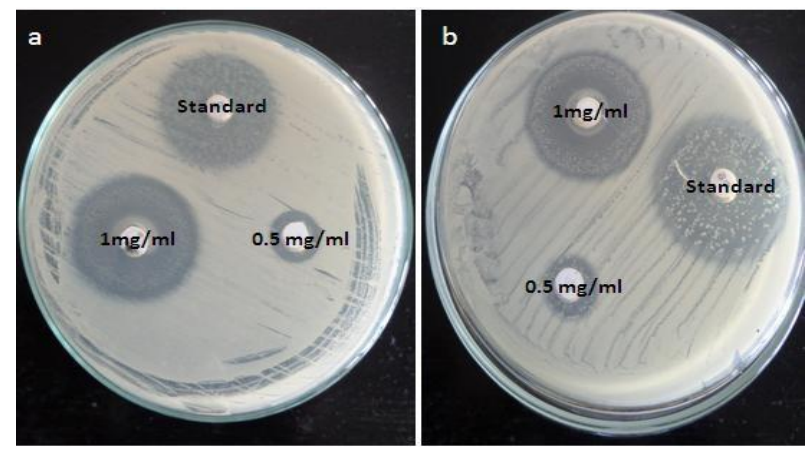

Fig. 4. Antifungal activity of LA-NPs against human pathogenic

In general, nanoparticles have the ability to anchor to the microorganisms such as bacteria or fungi cell wall and subsequently penetrate it, thereby causing structural changes in the cell membrane like the permeability of the cell membrane and death of the cell. There is formation of 'pits' on the cell surface, and there is accumulation of the nanoparticles on the cell surface (Sondi et al., 2004). Developing novel antibacterial agents against bacteria strains, mostly major food pathogens, such as Escherichia coli 0157: H, Campylobacter jejuni, Staphylococcus aureus, Pseudomonas aeruginosa, Enterococcus faecalis, Salmonella, and Clostridium perfringens, has become utmost demand (Hafez et al., 2014). The inhibition of microorganisms growth reported in this present study is dependent on the concentration of LA-NPs in the disk.

Nano-sized particles exhibit varying morphologies and show significant antibacterial activity over a wide spectrum of bacterial species explored by a large body of researchers (Buzea et al., 2007). The exact mechanism which nanoparticles employ to cause antimicrobial effect is not clearly known. However, various theories have been proposed on the action of nanoparticles on microbes to cause the microbial effect against human pathogenic bacteria and fungi.

\section{CONCLUSION}

In the present study, sol-gel route synthesized LA-NPs impregnated filter paper disk achieved maximum activity against $S$. aureus compared with other three tested organisms such as $S$. pyogenes, $E$. coli and $K$. pneumonia. The synthesized LA- NPs showed very good antimicrobial properties against studied fungi. At the concentration $1 \mathrm{mg} / \mathrm{ml}$ LA-NPs impregnated filter paper disk achieved maximum activity against human pathogen.

\section{REFERENCES}

Amna Sirelkhatim, Shahrom Mahmud, Azman Seeni, Noor Haida Mohamad Kaus, Ling Chuo Ann, Siti Khadijah Mohd Bakhori, Habsah Hasan and Dasmawati Mohamad, (2015). Review on Zinc Oxide Nanoparticles: Antibacterial Activity and Toxicity Mechanism. Nano-Micro Lett. 7(3):219242.

Brayner, R., (2008). The toxicological impact of nanoparticles, Nano Today, 3: 48-55.

Buzea, C., I. I. Pacheco, K. Robbie, (2007). Nanomaterials and nanoparticles: sources and toxicity. Biointerphases 2(4): MR17-MR71.

Duncan, T.V., (2011). Applications of nanotechnology in food packaging and food safety: barrier materials, antimicrobials and sensors. J. Colloid Interface Sci. 363(1): 1-24.

Fu, G., P.S. Vary, C.T. Lin, (2005). Anatase TiO2 nanocomposites for antimicrobial coatings. $J$. Phys. Chem. B 109(18): 8889-8898.

Gao, X., Y. Cui, R. M. Levenson, L. W. K. Chung, S. Nie, (2004). In vivo cancer targeting and imaging with semiconductor quantum dots. Nat. Biotech. 22:969-976.

Gayathri. S., and B. Chandar Shekar, (2015). Synthesis and Characterization of Lanthanum Aluminate Nanoparticles Prepared By Simple Sol-Gel Route. Int. J. Biosci. Nanosci. 2(6): 147 150

Hafez, E.E., H. S. Hassan, M. Elkady and E. Salama, (2014). Assessment Of antibacterial activity for synthesized zinc oxide nanorods against plant pathogenic strains. Int. J. Sci. Tech. Res., 3(9): 318-324.

Hostetler, M. J., J. E. Wingate, C. J. Zhong, J. E. Harris, R. W. Vachet, M. R. Clark, J. D. Londono, S. J. Green, J. J. Stokes, G. D. Wignall G. L. Glish, M. D. Porter, N. D. Evans and R. W. Murray, (1998). Alkanethiolate gold cluster molecules with core 
diameters from 1.5 to $5.2 \mathrm{~nm}$ : core and monolayer properties as a function of core size. Langmuir, 14:17-30.

Iconaru. S.L., A. M. Prodan, M. Motelica-Heino, S. Sizaret and D. Predoi, (2012). Synthesis andcharacterization of polysaccharidemaghemite composite nanoparticles and their antibacterial properties. Nanoscale Res. Lett. 7:1-8.

Kagan, V.E., H. Bayir and A. A. Shvedova, (2002). Nanomedicine and nanotoxicology: two sides of the same coin. Nanomedicine. 2(4): 397-401.

Kim, J.S., E. Kuk, K. N. Yu, J. H. Kim, S. J. Park and H. J. Lee, (2007). Antibacterial effects of silver nanoparticles. Nanomed. Nanotechnol. Bio. Med., 3(1): 95-101.
Maya Raman, Viswambari Devi and Mukesh Doble, (2015). Biocompatible $\quad$-carrageenan- $\gamma$ maghemite nano composite for biomedical applications-synthesis, characterization and in vitro anticancer efficacy. J. Nanobiotech. 13(18): 1-13.

Mrinmoy De., P.S. Ghosh and V.M. Rotello, (2008). Application of nanoparticles in biology. Adv. Mat. 20:4225-4241.

Savithramma N., M. Lingarao, S.K.M. Basha, (2011). Antifungal efficacy of silver nanoparticles synthesized from the medicinal plants. Der. Pharma. Chemica. 2:346-372.

Sondi, I. and B. Salopek Sondi, (2004). Silver nanoparticles as antimicrobial agent: a case study on E. coli as a model for Gram-negative bacteria. J. Colloid Interface. Sci. 275:177-182. 